\title{
DISCURSO EN EL SENADO SOBRE LA FORMACIÓN DE LA UNIDAD POPULAR
}

\section{SPEECH IN THE SENATE ON THE FORMATION OF THE POPULAR UNITY}

\section{Salvador Allende}

Pronunciado: el 6 de enero de 1970

Versión digital: Eduardo Riva, 2015

Esta edición: Marxists Internet Archive, 1 de enero de 2016

PALABRAS CLAVE: DISCURSO * CHILE * PARTIDO POLÍTICO

KEYWORDS: SPEECHES * CHILE * POLITICAL PARTIES

Señor Presidente, pocas veces en la vida política chilena ha habido mayor inquietud en vastos sectores ciudadanos ante las perspectivas del pueblo de expresar sus anhelos y sus ansias en la lucha presidencial que se avecina.

No deseo, ni sería pertinente, hacer un análisis relativo a la significación del esfuerzo unitario de partidos o grupos que, a nuestro juicio, evidentemente representan la mayoría del país. Tan sólo deseo señalar que, en mi opinión, en esta hora inquietante de nuestra vida nacional, se hace más necesario que nunca tener fe y confianza en la voluntad de las masas populares $y$ en la capacidad de sus dirigentes para enfrentar la responsabilidad histórica que tenemos los hombres de izquierda.

Hoy, desde el punto de vista personal, como precandidato del Partido Socialista, he tomado una resolución, condensada en un documento que me permitirá leer en el Senado, porque su contenido es de tipo político y porque ésta es nuestra tribuna. Sería petulancia de mi parte imaginar que los señores senadores se preocuparan de un problema de orden personal. Pero siendo, como es, una materia esencialmente política, quiero que mi pensamiento quede incorporado al Diario de Sesiones del Senado.

He entregado al conocimiento del país la siguiente declaración: La designación del candidato único de los partidos de izquierda ha provocado lamentables dificultades, después de los significativos avances que se alcanzaron con la redacción de un programa, del acuerdo acerca del carácter del futuro Gobierno Popular $y$ de un documento sobre la orientación de la campaña presidencial.

La circunstancia de que sea mi nombre el postulado por el Partido Socialista para aspirar a la representación unitaria y de que no se haya producido acuerdo en torno de la nominación, me han inducido a adoptar una actitud 
—ya conocida por mi partido- que creo necesario explicar públicamente.

Estoy cierto de que el Comité Central y los militantes del partido acordaron mi postulación teniendo presente mi invariable lealtad al socialismo, observada durante mi vida política y los esfuerzos que nunca escatimá en pro de la unidad popular.

Hace más de treinta años, me correspondió participar en forma activa en la erección del Frente Popular, movimiento unitario de izquierda que, con el sacrificio de legítimas aspiraciones de los partidos de la clase obrera - como el socialista - hizo posible el triunfo del Presidente Pedro Aguirre Cerda, en cuyo Gobierno tuve el honor de ser ministro de Salubridad, como personero de mi colectividad.

En 1952, en momentos difíciles para la clase trabajadora $y$ sus colectividades políticas, enfrenté la dura tarea de encabezar un movimiento de esclarecimiento ideológico, asumiendo su representación en una contienda sin posibilidad alguna de buen áxito electoral.

En 1958 y en 1964, fortalecido ya el proceso iniciado en 1951, me correspondió personificar al Frente de Acción Popular en dos campañas presidenciales, que si bien no culminaron en la conquista del poder, contribuyeron de manera decidida a esclarecer y ampliar el proceso revolucionario.

El esfuerzo para unificar los partidos populares tiene ahora importancia aún más relevante.

La Unidad Popular se plantea como la alternativa de un Gobierno diferente; es la conquista del poder para el pueblo, precisamente después que el país ha experimentado el fracaso del reformismo demócrata-cristiano y cuando aún están a la vista los resultados del anterior régimen, inspirados ambos en el capitalismo tradicional.

El panorama internacional nos señala la urgencia de enfrentar la intromisión imperialista, cada día más insolente y traducida en el fortalecimiento de las fuerzas represivas y contrarrevolucionarias y de la que es gráfica demostración el informe del gobernador Rockefeller.

El proceso unitario en desarrollo abarca una amplitud nunca antes alcanzada y muestra en su seno la definitoria gravitación de los partidos revolucionarios. Las proyecciones de estos últimos son producto, en buena cuota, de la acción conjunta desplegada durante más de 14 años por socialistas y comunistas. La unidad también aparece reforzada por la radicalización de los partidos de clase media; como consecuencia de la dramática realidad social que castiga también a sus militantes y simpatizantes.

Estas características diferencian nítidamente al proceso actual de anteriores experiencias, como el Frente Popular.

Los acuerdos suscritos por los partidos populares constituyen una expresión promisoria de los propósitos que orientan el proceso unitario.

Por lo mismo, se torna más extraño y lamentable que surjan dificultades en la designación de quien habrá de representar a los sectores de izquierda en la próxima elección presidencial.

Al no vislumbrarse acuerdo en las conversaciones bilaterales, de inmediato comuniqué a mi partido, hace días, la petición de que se considerara seriamente la expectativa de levantar la postulación de otro de sus miembros, solicitud que he reiterado con posterioridad.

La Comisión Política del socialismo no consideró que procedía acoger mi sugestión. También puse oportunamente en conocimiento del Partido Comunista mi actitud. Actuá de igual manera con algunos dirigentes del Partido Social Demócrata y con el senador don Luis Fernando Luengo, único parlamentario de esta misma colectividad.

El Partido Socialista nunca atribuyó al hecho de no apoyar en esta etapa una determinada candidatura, extraña a sus filas, el significado de un veto o descalificación, circunstancia que había implicado prepotencia política.

Durante la prolongada trayectoria cumplida con dedicación y esfuerzo incansable a favor de la Unidad Popular, nadie ha pretendido aplicar procedimientos discriminatorios.

En este momento tan trascendental para el proceso popular y para el país, no podría yo jamás asumir una actitud diversa de aquella que invariablemente he mantenido: consecuencia política y que es, sin duda, el mejor atributo 
que puedo exhibir después de tan dilatada participación en la lucha revolucionaria.

Fue seguramente la consideración de esta circunstancia la que indujo a mi partido a levantar, una vez más, mi nombre. En forma correlativa, por mi parte consideré que debía prestar, también una vez más, mi contribución a la causa a que siempre me he esmerado en servir con honestidad, decisión y clara conciencia doctrinaria.

En la misma medida en que estuve dispuesto a hacer el aporte personal que me correspondía, si se consideraba mi nombre como garantía para alcanzar el cumplimiento de las aspiraciones unitarias, he resuelto solicitar a la dirección de mi partido, como ya lo he hecho, que se prescinda de mí, si mi nombre constituye obstáculo para el logro de metas que se hallan muy por encima de todo personalismo y en las que están en juego el presente y el futuro de la clase trabajadora.

Al plantear esta petición a mi partido, lo he hecho porque pienso que en la actualidad no estamos empeñados en la mera lucha por elegir un Presidente de la República sino tras la conquista del poder para el pueblo, a fin de abrir caminos a un proceso efectivamente revolucionario, que inicie la construcción de la nueva sociedad chilena y que señale también una ruta para América Latina.

La tarea que tiene ante sí la Unidad Popular es de tal urgencia histórica, que, si no se cumple con prontitud, incontenibles tensiones sociales arrastrarán a Chile al caos, como consecuencia del fracaso del sistema.

Hasta un ciego puede ver las proyecciones $y$ el significado que han tenido $y$ tienen las huelgas del poder judicial y del regimiento Tacna. La hoguera de rebeldía juvenil no se apaga sino con su presencia activa y creadora en la construcción del socialismo.

Si los partidos que reivindican para sí la responsabilidad de vanguardia no son capaces de cumplir adecuada y unitariamente su papel revolucionario, surgirán en forma inevitable la insurgencia desesperada o la dictadura como proyección de la insuficiencia cada vez más notoria del régimen.
No es el camino de la asonada, sin conducción política responsable, la solución que puedan sustentar los verdaderos revolucionarios. Luchamos por crear el más amplio y decidido movimiento anti-imperialista, destinado a que se cumpla la revolución chilena. Los emboscados que hubieran podido llegar hasta nosotros, serán aplastados por la clarividencia revolucionaria del pueblo. No somos sectarios ni tampoco excluyentes; somos y seremos, sí, exigentes, para que en Chile el pueblo no aparezca burlado en sus ansias de independencia económica y política.

La dictadura contrarrevolucionaria no será capaz, por cierto, de abrir posibilidades al país ni de acallar, por el imperio de la fuerza, la legítima rebeldía de los chilenos altivos y combatientes.

El cuadro nacional nuestro es muy claro. La frustración se expresa desde el intelectual al campesino, y la juventud busca tácticas de lucha que señalan su decisión de desafiar resueltamente el actual estado de cosas, aunque aquéllas no sean las más convenientes para el desarrollo orgánico del proceso revolucionario. Quienes tenemos serias responsabilidades en el movimiento popular y hemos fundido nuestra suerte con la suya, nos hallamos más obligados aun para asumir una actitud de desprendimiento $y$ de consecuencia moral.

Es precisamente lo que estoy dispuesto a hacer. Al dar este paso de responsabilidad personal, reitero mi decisión de que, en caso de no alcanzarse la nominación de un candidato de unidad, hecho lamentable que nunca podría ser atribuido a intransigencias del socialismo, cumplirá las tareas que el partido me señale. Si en tales circunstancias se viera obligada nuestra colectividad a enfrentar separadamente la próxima elección presidencial y reitera su decisión de que yo lo represente, mis camaradas podrán contar, como siempre ocurrió, aun en los momentos y condiciones más difíciles y sacrificadas, con mi concurso para tan honrosa tarea partidaria.

Destaco, asimismo, la actitud del secretario general del partido y la dirección, en resguardo de mi candidatura. 
Por último, quiero agradecer a los miles y miles de chilenos, miembros o no de los partidos populares, $y$ a todos y cada uno de los socialistas su adhesión, expresada en las concentraciones multitudinarias realizadas a lo largo del país. A su lealtad de siempre, responderé con mi lealtad de siempre; no seré un desertor de la lucha revolucionaria, aunque no figure como candidato. Por el contrario, en tal situación, será para mí más imperativo seguir junto al pueblo. Nuestra responsabilidad se acrecienta, sobre todo en momentos en que sólo se descubren horas caracterizadas por amenazas reaccionarias o dictatoriales que, de concretarse, significarán violencia y represión contra la juventud $y$ los trabajadores.

Personalmente, sólo aliento un anhelo íntimo: que vaya donde vaya, esté donde estuviere, seguiré siendo para el pueblo el "compañero Allende". 